\title{
O professor real e o ideal na visão de um grupo de graduandos de enfermagem*
}

\author{
THE REALAND THE IDEALIZED TEACHER AS ENVISIONED BY A GROUP OF GRADUATING NURSES
}

EL PROFESOR REAL Y EL IDEAL EN LA VISIÓN DE UN GRUPO DE ALUMNOS DE ENFERMERÍA

\section{Joyce Maria Worschech Gabrielli' ${ }^{1}$ Nilza Teresa Rotter Peláa}
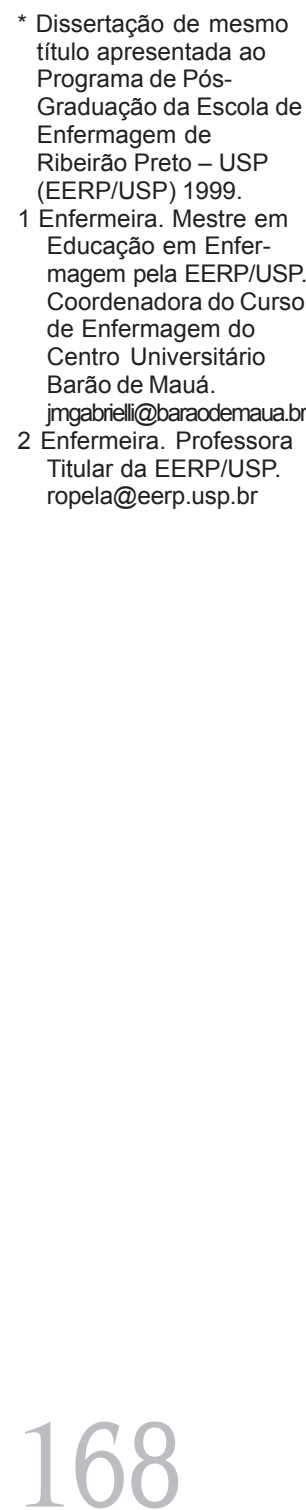

Rev Esc Enferm USP 2004; 38(2): 168-74.

\begin{abstract}
RESUMO
O presente estudo constituiu-se em uma pesquisa não experimental, do tipo "survey". Busca contribuir para o crescimento do conhecimento sobre o ensino de enfermagem caracterizando o professor real e o idealizado por um grupo de graduandos de enfermagem, identificando a área mais valorizada pelo aluno de enfermagem no desempenho docente: afetiva ou relacionada ao domínio teórico-prático do conhecimento especifico e aos aspectos didático-pedagógicos, bem como identificando diferenças de atitudes entre os graduandos em relação à essa valorização. Os dados foram obtidos pela aplicação de um questionário a 69 graduandos de duas escolas distintas. Concluiu-se que os aspectos afetivos da relação professoraluno são mediadores para que, através do domínio tanto do conteúdo da disciplina, como dos aspectos didáticopedagógicos pelos docentes, $o$ processo ensino-aprendizagem se concretize com sucesso.
\end{abstract}

\section{PALAVRAS-CHAVE}

Ensino.

Docente de enfermagem.

Estudantes de enfermagem.

\begin{abstract}
This survey, carried out in two colleges of nursing, is an attempt to contribute to the understanding of the teaching of nursing by characterizing the real and idealized professor, as seen by undergraduate students; identifying the most valued areas of the teacher's performance: the emotional side or that related to specific theoretical-practical prowess and the didacticpedagogic aspects as well as identifying the differences in attitudes between the students in relation to these values. The data were obtained through the application of 69 ques-tionnaires. After descriptive analysis of the results, it was concluded that the emotional aspects of the teacher-student relationship are mediators through which the mastery of the subject content and also the didacticpedagogic aspects, as well as, the teaching-learning process are achieved with success.
\end{abstract}

\section{KEYWORDS}

Teaching.

Faculty, nursing.

Students, nursing.

\section{RESUMEN}

Esta investigación de tipo survey, tuvo como objetivos verificar las características de los profesores mas valorizadas por alumnos de enfermería de dos escuelas y detectar diferencias marcantes de actitudes entre ellos, en relación a esa valorización. Los autores concluyeron que los aspectos afectivos de la relación profesor-alumno son mediadores, para que, a través del domínio por los docentes del contenido de la disciplina, como de los aspectos didáctico-pedagógicos, el proceso de enseñanzaaprendizaje se concretice con éxito. Fue evidenciado aún que los aspectos afectivos, cuando son orientados negativamente, pueden inviabilizar el proceso. Fue constatado también que no hay diferencias marcantes entre las actitudes de los alumnos de las dos escuelas estudiadas.

\section{PALABRAS CLAVE}

Enseñanza.

Docente de enfermería.

Estudiantes de enfermería. 


\section{INTRODUÇÃO}

Atuando na docência, sempre inquietounos a questão da qualidade do profissional enfermeiro que está sendo formado; ministrávamos aulas teóricas procurando enriquecê-las com exemplos reais de nossa vida profissional, valorizando muito essa "ponte" entre teoria e prática, em detrimento das questões relativas aos aspectos afetivos do relacionamento professor-aluno.

Quando passamos a ouvir melhor nossos alunos, começamos a perceber como e quanto a afetividade era importante na relação professor-aluno.

Havia, nessas falas, denúncias do comportamento docente definido por alguns autores $^{(1)}$ como insegurança no relacionamento com os alunos por falta de capacitação didática. Desse modo, assumem uma postura muito formal no trato com os estudantes, lançando mão de cinismo ou sarcasmo para controlar os rebeldes, apresentando alto índice de exigência nas provas, acreditando que atuando dessa forma, possam manter sua "autoridade". No outro extremo, o professor, didaticamente inseguro, mostra-se extremamente tolerante, tanto com indisciplina, quanto com as ausências, com baixíssimo nível de exigência no trabalho, facilitando sobremaneira as provas, adotando assim uma postura humilde e submissa perante seus alunos.

Entendemos que o dilema entre a formação do técnico competente e do profissional competente, estreita-se muito na educação do enfermeiro, ficando mesmo difícil para alguns docentes fazer a distinção.

A maioria de nossos estudantes de enfermagem carece de senso crítico e estão habituados apenas a ouvir, decorar e copiar, ao invés de participar de discussões ${ }^{(2)}$.

Levamos em consideração no ensino da enfermagem, todas essas dificuldades acima expostas, mas, não podemos aceitá-las como justificativas para as "queixas" dos alunos em relação ao comportamento de alguns docentes, dificultando, obstruindo, inviabilizando a aprendizagem dos estudantes.

Buscamos, então, compreender, do ponto de vista do aluno, o que seria facilitador para sua aprendizagem, em relação ao comportamento docente.
Frente a dados da literatura ${ }^{(1-8)}$, aceitamos o desafio de, colocando-nos sub judice enquanto professores, buscarmos respostas para entendermos de que maneira nossas características, comportamentos e atitudes poderiam facilitar ou dificultar o processo de aprendizagem do aluno.

Demos, então, início a esta pesquisa, com a proposta de procurar compreender qual seria a área mais valorizada pelo aluno, graduando de enfermagem, no desempenho docente: a afetiva ou a instrumental. Aqui, instrumental relacionada aos domínios teórico-práticos do conhecimento específico e aos aspectos didático-pedagógicos.

\section{OBJETIVOS}

I. Identificar as características, comportamentos e atitudes que caracterizam o professor ideal e o professor real na visão de um grupo de graduandos de enfermagem;

II. Identificar a área mais valorizada pelo aluno de enfermagem no desempenho docente: afetiva ou instrumental (esta última relacionada ao domínio teórico-prático do conhecimento específico e aos aspectos didático-pedagógicos).

III. Detectar diferenças marcantes de atitudes, em relação à essa valorização, entre os graduandos de enfermagem de duas escolas distintas.

\section{MATERIALE MÉTODO}

Este estudo constitui-se em uma pesquisa não experimental, do tipo "survey" descritivo.

\section{Campo de Estudo}

Desenvolvemos o presente trabalho junto a graduandos de enfermagem do ano de 1997, alunos das duas escolas de enfermagem existentes no município de Ribeirão Preto, Estado de São Paulo, sendo uma instituição de ensino privada e outra pública.

\section{Amostragem}

A população de nosso estudo foi composta por 65 alunos matriculados no $8^{\circ}$ semestre da escola pública, e por 42 alunos regularmente matriculados na $4^{\mathrm{a}}$ série da escola privada.
O professor real e o ideal na visão de um grupo de graduandos de enfermagem 
Joyce Maria W. Gabrielli Nilza Tereza Rotter Pelá
A amostra deste trabalho foi constituída por 38 alunos $(58,4 \%)$ da escola pública e 33 alunos $(80,4 \%)$ da escola privada.

\section{Procedimentos}

\section{Instrumentos de Coleta de Dados}

Após obtermos autorização da autora ${ }^{(9)}$, adaptamos o instrumento de coleta de dados por ela utilizado. Para compor o instrumento de coleta de dados do presente estudo, dos 60 itens descritivos de caracte-rísticas, comportamentos e atitudes que podem ser apresentados pelo professor, listados no instrumento original, destacamos os 37 itens pertencentes às categorias I, II e III, por serem esses domínios (cognitivo, didático-pedagógico e afetivo) os que nos interessavam.

Assim, o instrumento de coleta de dados que utilizamos foi composto por quatro etapas: as duas primeiras, referentes às expectativas dos graduandos em relação às características e atitudes desejáveis e indesejáveis de um professor (visão ideal), e as outras duas, às percepções dos graduandos em relação aos seus professores (visão real).

\section{Processo de Coleta de Dados}

Após autorização formal de ambas as escolas e orientação aos graduandos que sua partici-pação era voluntária, os dados foram coletados em novembro de 1997. Na escola privada, o questionário foi aplicado por uma professora na sala de aula, e recolhido pela mesma após terem sido respondidos pelos graduandos que estavam presentes e que concordaram livremente em participar da pesquisa.

$\mathrm{Na}$ escola pública, o instrumento de coleta de dados foi distribuído pela pesquisadora, que, por não ter autorização para utilizar o espaço da aula para que os alunos respondessem ao questionário, teve dificuldades no retorno dos mesmos. Foram distribuídos nesse primeiro dia, 62 questionários para os graduandos que, divididos em duas turmas (cada turma cursando um disciplina) estavam na escola naquela data e que também concordaram espontaneamente em participar do estudo. Conforme solicitação dos próprios alunos, foi marcada nova data para o recolhimento desses questionários. Na data marcada, conseguimos um retorno insatisfatório, pois muito alunos haviam esquecido de levar os questionários ou ainda não o haviam respondido. Nova data foi agendada. Cabe ressaltar que a época escolhida para a coleta de dados, apesar de interessante para a pesquisa (final do último semestre, quando os alunos já vivenciaram todo o curso), dificultou a participação dos graduandos, justamente por coincidir com as últimas provas e finalização dos estágios.

Apesar da cooperação dos docentes responsáveis pelas disciplinas, que além de lembrarem aos alunos para que trouxessem os questionários, ainda se dispuseram a recebê-los, obtivemos pouco sucesso. Então, de posse das escalas dos estágios dos referidos alunos, fomos por três vezes, em dias previamente anunciados, ao hospital público onde eram realizados os supracitados estágios, e percorremos todos os andares, abordando pessoalmente cada graduando. Mesmo com todo o esforço da pesquisadora e das docentes da referida escola pública, obtivemos o retorno de 38 (trinta e oito) questionários dos 62 distribuídos, sendo que um foi entregue em branco por uma aluna que apenas assinou seu nome no instrumento. Ainda assim, no início do ano seguinte, conseguimos os telefones e endereços dos alunos, mas mesmo através de solicitação via fone, não logramos recolher mais nenhum questionário.

Assim, nossa amostra constituiu-se de 71 sujeitos, sendo 33 da escola privada, aqui denominada escola A e 38 da escola pública, escola B.

Solicitamos então, a assessoria de um estaticista $^{(a)}$ para avaliar e validar o tamanho da presente amostra. "O principal elemento a ser levado em conta na avaliação de uma amostra, é sua representatividade" ${ }^{\text {(10) }}$, ou seja, o quanto ela é similar em suas características ou se comporta como a população estudada. Partindo dessa premissa e considerando sua própria experiência, o estaticista considerou que, mesmo conseguindo um maior número de sujeitos, ou até sua totalidade, seria pequena a probabilidade de haver mudanças, ou seja, não teríamos obtido dados significativamente diferentes dos encontrados. Dessa forma, acreditava que, para o foco de nosso estudo, nossa amostra seria representativa. 


\section{Tratamento dos Dados}

Utilizamos o programa de computação Epi Info ${ }^{(11)}$ para análise quantitativa dos dados, através de técnicas de estatística descritiva.

Dessa forma, pudemos agrupar e cruzar os dados, obtendo os resultados apresentados a seguir.

\section{RESULTADOS}

\section{Os professores ideais}

De acordo com os dados coletados que visam caracterizar o professor desejado, idealizado, pelos graduandos, sujeitos desta pesquisa, parece-nos que, segundo a classificação e a freqüência com que ocorreram as características, comportamentos e atitudes consideradas como mais positivas, desejadas, para os professores pelo grupo de graduandos estudado, estas se referem aos domínios do conhecimento específico e dos aspectos didático-pedagógico. Porém, em relação às características e atitudes consideradas como mais negativas e indesejáveis, mereceram destaque aquelas relacionas aos aspectos afetivos do relacionamento professor-aluno, mostrando que, quando negativamente orientadas, essas relações poderão constituir-se em grandes obstáculos, dificultando o aprendizado do aluno. Essa constatação vem ao encontro do que dizem vários autores ${ }^{(4,9,12-17)}$.

Encontramos na literatura trabalho de pesquisa evidenciando que os alunos desejam muito serem respeitados pelos professores, serem tratados como pessoas únicas que são, sem sofrerem "ameaças", "policiamento", declarando assim, um melhor rendimento escolar ${ }^{(18)}$.

Outro trabalho encontrado ${ }^{(12)}$ corrobora nossos resultados ao colocar que o aluno não deseja o professor "bonzinho", mas sim, aquele "intelectualmente capaz e afetivamente maduro".

Alguns autores ${ }^{(17)}$ trazem em seu estudo que as "melhores" características dos professores, na opinião dos alunos são competência e habilidades clínicas; demonstrar autoconfiança; ser responsável e acessível, e as piores, se referem a : fazer críticas sobre os erros dos alunos, não conseguir entusiasmá-los, ser antipático, inacessível, não conseguir respeito mútuo.
O fato dos alunos serem tratados como pessoas, desenvolvendo assim, um favorável relacionamento interpessoal professor-aluno, é um fator facilitador da aprendizagem, nos dizeres dos próprios alunos ${ }^{(19)}$.

Nossos resultados concordam com os de alguns autores ${ }^{(3)}$ que apresentam aspectos do desempenho do papel do professor, tais como conhecimento do conteúdo, clareza e pertinência das explicações, capacidade para despertar o interesse e motivar o aluno, os quais têm maior peso para os alunos mais velhos, do que para alunos dos primeiros anos de estudo.

Também na opinião dos alunos estudados por outro autor ${ }^{(12)}$, que despertou nosso interesse para o presente estudo, ter domínio do conteúdo teórico-prático e possuir habilidades didático-pedagógicas, foram características consideradas necessárias a um bom professor universitário, além de ser paciente, tolerante, amigo, flexível e afetuoso.

Mas, afinal, quem é o professor desejado? "O que eles querem é um professor capaz e afetivamente maduro" ${ }^{(12)}$.

Após a análise dos resultados, o que ficou, no nosso entender, pode ser resumido no dizer acima. É incontestável que, para nosso grupo de graduandos, o professor ideal deve, sobretudo, dominar profundamente a disciplina que ensina.

Ao longo de nosso estudo, isso ficou muito evidente, como ficou também que este mesmo professor deve dominar técnicas didático-pedagógicas, para que o processo ensino-aprendizagem se complete com sucesso. Contudo, se as características e atitudes relativas aos aspectos afetivos da relação professor-aluno, em sua vertente positiva, não aparecem em destaque para caracterizar o professor desejado, aparecem em primeiro plano em sua versão negativa, ou seja, denunciando o quanto os alunos rejeitam a "falta de respeito" e de consideração para com eles, o seu desagrado ao serem "expostos", "discriminados", "humilhados" pelos professores.

Esses resultados que obtivemos, vêm ao encontro do que foi descrito também por vários outros autores ${ }^{(9,14-15,19)}$.

Os alunos desejam que seus professores os tratem como seres humanos que são,
O professor real e o ideal na visão de um grupo de graduandos de enfermagem 
Joyce Maria W. Gabrielli Nilza Tereza Rotter Pelá diferentes entre si, com diferentes histórias, conhecimentos prévios, e não como simples discentes, folhas em branco onde o professor escreverá...

Ao longo de nossas leituras, percebemos que o aluno não deseja negar a autoridade de seus professores. O que ele rejeita é o autoritarismo que permeia essa relação, "engessando" o aluno, tirando-lhes o direito de expressão, fazendo com que este tenha um comportamento "dócil", "manso", acatando, dessa forma, todas as práticas pedagógicas, mesmo que desmotivantes, entediantes, sem contestá-las. O aluno simplesmente "cumpre as regras do jogo", sem se preocupar em adquirir o conhecimento, mas sim desejando o término do curso o mais rápido possível, obtendo, assim, ascensão social. Dessa forma, não consegue vislumbrar o impacto que isso terá em seu desempenho na futura vida profissional ${ }^{(18)}$.

\section{Os professores reais}

De acordo com nossos resultados, podemos ressaltar que:

- os melhores professores, segundo percepção dos graduandos de ambas as escolas, possuem características e atitudes consideradas como as mais positivas e desejadas para o professor ideal, porém, a freqüência com que seus professores as apresentam em seu comportamento, deixa a desejar, já que "raramente" ou apenas "alguns", contemplam essas características em sua atividade docente. Além disso, mesmo classificados como melhores, esses profes-sores apresentam características e atitudes consideradas com muito negativas $(\mathrm{N}-$ ) ou negativas $(\mathrm{N})$, por mais de $85 \%$ dos sujeitos da amostra. São elas: "aplicam provas que exigem memorização e repetição das aulas e utilizam apenas um instrumento de avaliação", características estas que estão presentes no comportamento de "todos" ou "quase todos" os seus professores, segundo mais de $47 \%$ dos graduandos de ambas as escolas.

- em relação aos piores professores, um fato positivo: mesmo classificados como "piores", apresentam no seu "fazer" docente, segundo o grupo de graduandos estudado, características, comportamentos e atitudes positivas importantes, tais como, utilizar linguagem fácil, acessível, ter conhecimento sobre pesquisas recentes no seu campo do saber, ter domínio do conteúdo da disciplina que leciona, expor objetivos da disciplina, relacionando-os com a prática, entre outras. Estas características ressaltadas são relativas ao domínio do conteúdo específico da disciplina e aos aspectos didático-pedagógicos, o que, para nós, indica que talvez os piores professores, assim são considerados pelos alunos estudados, por possuírem características negativas relacionadas aos aspectos afetivos do relacionamento professor-aluno.

\section{CONCLUSÕES}

Assim, analisando nossos resultados, concluímos que:

- o professor ideal, para o nosso grupo de graduandos de enfermagem, é aquele que conhece profundamente a disciplina que leciona, tem clareza e linguagem fácil em suas explicações, admite e demonstra haver maneiras diferentes de ensinar, demonstra segurança e domínio de si na condução do ensino, não faz discriminações entre alunos, não é irônico, indelicado e não humilha o aluno, sabendo organizar o ensino e, por fim, que não grite, ameace, ou seja grosseiro com seus aprendizes;

- os percentuais que, segundo os graduandos, indicam a freqüência com que as características e atitudes consideradas negativas, indesejadas no comportamento do professor ideal estão presentes em "alguns" ou "quase todos" os seus professores são, na nossa opinião, altos, dando-nos indícios de que o que supúnhamos é verdadeiro: o ensino continua "bancário", centrado no professor, onde nós, os professores, damos as aulas, ditamos as regras, guiamos, dirigimos, aprovamos ou reprovamos, ficando o aluno como mero espectador, passivo, quase sem nenhuma responsabilidade em sua aprendizagem $^{(18,20)}$.

- as características e atitudes relativas aos aspectos afetivos do relacionamento professor-aluno são mediadores, para que, através dos domínios do conteúdo específico da disciplina e dos aspectos didáticopedagógicos, o processo ensino-aprendizagem se concretize com sucesso. Destacamos o caráter obstrutor das características, comportamentos e atitudes relativas aos 
aspectos afetivos da relação professoraluno, quando negativamente orientadas, dificultando sobremaneira, ou mesmo inviabilizando os sucessos na aprendizagem do aluno;

- não há diferenças marcantes entre as atitudes dos graduandos das duas escolas estudadas.

Com esse trabalho esperamos contribuir, se não provocando mudanças bruscas no comportamento docente, suscitando, ao menos, uma reflexão profunda enquanto educadores que somos, sobre como conduziremos nosso ensino, que caminhos escolheremos, quais posturas adotaremos, como conduziremos nosso relacionamento com nossos aprendizes.

Não nos permitimos generalizações de nossos resultados, mas, através da caracterização do professor real e do ideal pelo nosso grupo de graduandos, esperamos "dar pistas" de como nossas características e atitudes, em nosso comportamento enquanto docentes, poderão fazer de nós os professores inesquecíveis na memória de cada um de nossos alunos.

Concordamos com o dizer:

é fundamental neste final de século, que os professores nas escolas ensinem a paixão pelo conhecimento. É função do mestre ser muito mais que um administrador de informações, ele precisa ser um administrador de curiosidades ${ }^{(21)}$.

Esses professores, ao nosso ver, seriam os professores inesquecíveis.
Esperamos que cada um de nós, professores, possamos refletir sobre nosso desempenho docente, perguntando a nós mesmos se conhecemos realmente quem são nossos alunos, por que alguns são bons alunos e outros não, quanto de nosso tempo temos dedicado a ouvir o aluno, a "perceber" e tentar "decodificar" suas mensagens, construindo nosso ensino em "conjunto" com eles, buscando assim, alcançar o objetivo comum a aprendizagem do educando, sua apreensão do conhecimento, seu crescimento enquanto ser humano.

Este trecho que encontramos em nossas leituras ${ }^{(18)}$ expressa, de maneira encantadora, tudo aquilo em que acreditamos, e esperamos que, um dia, seja a nossa maneira de colaborarmos para a formação de nossos enfermeiros.

O ato de semear a terra, lançar as sementes e colher os frutos não se dá sem investimento. Esse investimento depende de variáveis climáticas, depende da qualidade da terra (que pode ser melhorada, nutrida e revolvida), depende da semente, da época correta a ser plantada e colhida. Cabe ao jardineiro ajudar a natureza, através de seu gesto de amor. Esta tarefa, ele não delega. Nem ele se cansa de repetir cada etapa do processo. Rega as plantas, observa e retira as ervas daninhas, acompanha o crescimento e comemora cada novo botão. Não há como ignorar que a mão do jardineiro, a mão que planta e colhe, protege, recupera ou arranca, essa mão é guiada pela razão e pelo coração, pela experiência que o jardineiro acumula e que o faz sábio, mas que é regida também pelo profundo amor e prazer que sente, ao colher os frutos de seu jardim.
O professor real e o ideal na visão de um grupo de graduandos de enfermagem

\section{REFERÊNCIAS}

(1) Bordenave JD, Pereira AM. Estratégias de ensino-aprendizagem. $16^{\mathrm{a}}$ ed. Rio de Janeiro: Vozes; 1995.

(2) Waldow VR. Desenvolvimento do pensamento crítico na enfermagem. In: Waldow VR, Lopes MJM, Meyer DE. Maneiras de cuidar, maneiras de ensinar: a enfermagem entre a escola e a prática profissional. Porto Alegre: Artes Médicas; 1995. p. 109-34.
(3) Coll C, Miras M. A representação mútua profesor-aluno e suas repercussões sobre o ensino e a aprendizagem. In: Coll C, Palacios J, Machesi A, organizadores. Desenvolvimento psicológico e educação: psicologia da educação. Trad. de Angélica Mello Alves. Porto Alegre: Artes Médicas; 1996. v.2, cap.16, p. 265-80. 
Joyce Maria W. Gabrielli Nilza Tereza Rotter Pelá
(4) Galperin MRO, Pereira RCJ, Waldow VR. Avaliação da disciplina Assistência de Enfermagem ao Adulto I : estudo comparativo. Rev Gaúcha Enferm 1989; 10(2):50-61.

(5) Lanthier MGC. O professor de enfermagem: atuação em campo clínico. Rev Bras Enferm 1984; 37(1):2-11.

(6) Montero ML. Comportamento do professor e resultados da aprendizagem: análise de algumas relações. In Coll C, Palacios J, Machesi A. organizadores. Desenvolvimento psicológico e educação: psicologia da educação. Trad.de Angélica Mello Alves. Porto Alegre, Artes Médicas; 1996. v. 2, cap.14, p. 222-43.

(7) Saupe R. O cotidiano de ensinar e aprender enfermagem. Rev Gaúcha Enferm 1994; 15 (1/2):27-33.

(8) Tavares MSG, Ruffino MC, Santos BMO, Casagrande LDR. Indicadores para reestruturação do currículo de graduação em enfermagem: expectativas dos profissionais e apreciação do currículo por ex-alunos. Rev Gaúcha Enferm 1988; 9(1):36-42.

(9) Grigoli JAG. A sala de aula na Universidade na visão dos seus alunos: um estudo sobre a prática pedagógica na Universidade. [tese] São Paulo(SP):Pontifícia Universidade Católica de São Paulo; 1990

(10) Polit DF, Hungler BP. Fundamentos de pesquisa em enfermagem. Trad. de Regina Machado Garcez. $3^{\mathrm{a}}$ ed Porto Alegre: Artes Médicas; 1995. Planos de amostra; cap.7, p. 141-60.

(11) Dean AG, Dean JA, Coulombier D, Brendel KA, Smith DC, Burton AH et al. Epi Info Version 6:a word processing database, and estatístics program for epidemiology on microcomputers. Atlanta: Center of Disease Control and Prevention; 1994.
(12) Cunha MI. O bom professor e sua prática. $2^{\mathrm{a}}$ ed. Campinas: Papirus; 1992.

(13) Abreu MC, Masetto MT. O professor universitário em aula: prática e princípios teóricos. $8^{a}$ ed. São Paulo: MG Associados; 1990.

(14) Klausmeier HJ, Goodwin W. Manual de psicologia educacional: aprendizagem e capacidades humanas. Trad. de Maria Célia Teixeira Azevedo de Abreu. São Paulo: Harper \& Row do Brasil; 1977. Características do professor e interações com alunos; cap. 7, p. $197-222$.

(15) Mogan J, Knox JE. Characteristics of "best" and "worst" clinical teachers as perceived by university nursing faculty and students. J Adv Nurs 1987; 12(3):331-7.

(16) Rangel M. Representações e reflexões sobre o bom professor. Petrópolis: Vozes; 1994.

(17) Rogers CR. Liberdade para aprender. Trad. de Edgar de Godói da Mata Machado e Márcio Paulo de Andrade. $2^{\mathrm{a}}$ ed. Belo Horizonte: Interlivros; 1973.

(18) Sordi MR. A prática de avaliação do ensino superior: uma experiência na enfermagem. São Paulo: Cortez/Campinas: PUCAMP; 1995.

(19) Matheus MCC. A relação com a professora transforma a disposição interna da aluna para enfrentar os desafios da aprendizagem. [dissertação] São Paulo(SP): Escola de Enfermagem da USP, 1995.

(20) Tavares MSG, Rolin EJ, Franco LHR, Oliveira FL. O perfil do aluno ingressante nos Cursos Superiores de Enfermagem do Estado de São Paulo: 1993. Rev Paul Enferm 1995; 14(2/3):55-65.

(21) Masetto MT. Aulas vivas. São Paulo: MG Associados; 1992.

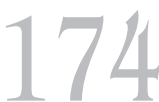

Rev Esc Enferm USP 2004; 38(2): 168-74. 